\title{
Emission of toxic sulfur gases from polymers coming in contact with food products and with infants
}

\author{
R. Houriet ${ }^{1, *}$ and D. Louvier ${ }^{2}$ \\ ${ }^{1}$ Laboratoire de Technologie des Poudres, Département des Matériaux, \\ École Polytechnique Fédérale de Lausanne, CH-1015 Lausanne, Switzerland \\ ${ }^{2}$ Laboratoire Emballage et Conditionnement, École d'Ingénieurs du Canton de Vaud, \\ CH-1400 Yverdon-les-Bains, Switzerland
}

\begin{abstract}
The analysis of the volatiles evolved from a number of polymer samples commonly used in domestic applications show that carbon disulfide, $\mathrm{CS}_{2}$, and carbonyl sulfide, $\mathrm{COS}$, are emitted in the lower range of temperatures, i.e. from room temperature up to $150{ }^{\circ} \mathrm{C}$. Emission of $\operatorname{COS}$ in the ppm range was also monitored from materials used in the fabrication of the teats for baby's feeding bottles and from similar devices. Given the lack of legal tolerance limits on the toxicity of COS, it is urgent that such norms be set for this compound.
\end{abstract}

\section{Introduction}

The toxicity of the constituants (polymers and additives) of polymer materials is well documented. However, there is relatively little information concerning the gaseous compounds evolved from these materials with the exception of extreme conditions such as high temperature and fire conditions.

Given the fact that non-negligible quantities of carbon sulfide, $\mathrm{CS}_{2}$, are used in the manufacturing of polymers such as rubber compounds during their vulcanization process, we tried to evaluate the emission of sulfur gases from rubber samples used in domestic applications in the conditions of their common temperature conditions (from ambient up to approximately $150^{\circ} \mathrm{C}$ ).

\section{Experimental}

\section{Gaseous emission from rubber compounds}

Two main categories of samples were studied. $1^{\circ}$-rubber gaskets coming in contact with food products (e.g. in coffee machines, pressure cooker, etc.) and $2^{\circ}$-rubber teats and related items made out of latex compounds coming into direct contact with infants, thereafter designated as teats.

\section{Measuring conditions and analytical methods}

The samples were taken from rubber items bought in department stores. A known quantity of the order of $1 \mathrm{~g}$ was placed in a $20 \mathrm{~mL}$ vial which was then sealed. The sample was equilibrated with its gas phase at $80^{\circ} \mathrm{C}$ for a period of
20 minutes. The head space, HS, i.e. the gaseous phase, was then injected into three types of analyzers:

1) a head space sampler, HS 40 XL (Perkin Elmer) coupled to a gas phase chromatograph, Autosampler XL (Perkin Elmer), the HS/GC technique;

2) a mass spectrometer, Thermolab (TA Instruments), the HS/MS technique;

3) an infra-red spectrometer, Nicolet 510 FTIR, equipped with a gas cell, the HS/FTIR technique.

Complementary measurements were performed using the coupling between a pyrolyzer, Pyroprobe 200 from CDS Instruments, and the mass spectrometer, the PY/MS technique. In this case, the polymer sample was heated directly in the pyrolyzer and the evolved gas phase analyzed with the MS.

The infra-red spectra of all the solid samples were also measured in the diamond-ATR mode (Golden Gate accessory from Graseby-Specac) in order to identify their class of polymers.

\section{Results}

We examined 11 samples of type 1 (gaskets, including 3 septa used in the laboratory) and 4 samples of type 2 (latex teats). The infra-red spectra indicate that all samples belong to the class of polyolefinic polymers (polyisoprene, polybutadiene) some of which obviously being copolymers and/or containing either a cellulose load (samples 1, 3, 6a, 21 and 23 ), or a mineral load, (as sample $6 \mathrm{~b}$ probably containing

* Correspondence and reprints.

Received May 06, 1999; revised May 10, 1999; accepted May 25, 1999. 


\section{Original articles}

ammonium tetrafluoroborate). On the other hand, samples 5 and 22 are most probably made out of pure polyethylene.

\section{HS/MS results}

Two sulfur gaseous compounds could be detected, i.e. carbonyl sulfide, COS detected at a mass to charge ratio, $m / z=60$, and carbon sulfide, $\mathrm{CS}_{2}$ at $\mathrm{m} / z=76$. One such example is shown in figure 1 for sample 1 . The chemical identity of these two gases was later confirmed in the HS/FTIR measurements, vide infra. The relative quantities of $\mathrm{COS}$ and $\mathrm{CS}_{2}$ emitted by all examined samples are reported in Table $\mathrm{I}$.

At this point, it is worth noting that both compounds COS and $\mathrm{CS}_{2}$ are emitted by the majority of materials commonly used in domestic applications, including the laboratory equipment! (septa). More recently developed materials such as samples 5 and 22 no not show such emissions.

The results obtained from teats-like samples (samples 20 to 23) indicate that the problem encountered with the emission of $\mathrm{CS}_{2}$ has been recognized and solved in these formulations. However, emission of COS from these samples to an amount similar to that evolving from the type 1 samples (gaskets) demonstrate that this problem of COS emission has been fully overlooked.

\section{HS/FTIR results}

Carbonyl sulfide is readily identified by its absorption peak doublet at 2070 and $2052 \mathrm{~cm}^{-1}$. Figure 2 shows the COS spectrum in this wawenumber domain as well as the spectra obtained from samples 1 and 20 to 23. Emission of COS is unambiguously detected. The HS/FTIR results obtained from the other samples corroborate those from the HS/MS measurements reported in Table I.

\section{HS/GC results}

Although the experimental conditions (column and detector) were not yet optimized for the separation of sulfur compounds, both $\mathrm{COS}$ and $\mathrm{CS}_{2}$, could be clearly identified. Improvements are in progress in order to quantify the emissions by this technique.

\section{PY/MS results}

We measured the two samples showing the largest emission of sulfur gases, i.e. the teething bearcub, sample 21, and the pressure cooker gasket, sample 1.

Figure 3 shows the evolution of COS emission as a function of temperature from 50 up to $150{ }^{\circ} \mathrm{C}$ for sample 21 . It can be seen that COS emission increases steadily with temperature reaching a maximum at about $100{ }^{\circ} \mathrm{C}$. Complementary measurements showed that the emission rate at $37^{\circ} \mathrm{C}$ is about one third of that determined at $80^{\circ} \mathrm{C}$. These results reinforce the conclusion that there is a real problem of ingestion of COS by an infant sucking such an item.
Table I. Emission of COS et $\mathrm{CS}^{2}$ as detected by HS/MS.

\begin{tabular}{llcc}
\hline$l^{\circ}$-gaskets & $\begin{array}{c}C O S \\
(\mathrm{~m} / z=60)\end{array}$ & $\begin{array}{c}\mathrm{CS}_{2} \\
(\mathrm{~m} / z=76)\end{array}$ \\
\hline $1-$ & pressure cooker & $8^{\mathrm{a})}$ & $7^{\mathrm{a})}$ \\
$2-$ & jar (preserve) & 4 & 2 \\
$3-$ & coffee machine & 2 & $\mathrm{tr}$ \\
$4-$ & bakery spatula & - & 4 \\
$5-$ & bottle stopper & 6 & - \\
$6 \mathrm{a}-$ & sealing stopper, lower part & - & 4 \\
$6 \mathrm{~b}$ & sealing stopper, upper part & - & 4 \\
10 & new septum, translucent & - & - \\
11 & new septum, white colour & 1 & - \\
12 & older rubber septum & 1 & 0.5 \\
13 & older jar gaket for marmelade & $\mathrm{tr}$ \\
\hline $2^{\circ}$-teats-like & $(\mathrm{COS} / z=60)$ & $(\mathrm{m} / z=76)$ \\
& & 3.5 & - \\
\hline $20-$ & teat of baby's feeding bottle & 10 & - \\
$21-$ & teething bearcub & - & - \\
$22-$ & baby bottle's beak & 3 & $\mathrm{tr}$ \\
$23-$ & dummy & & \\
\hline
\end{tabular}

a) arbitrary units.

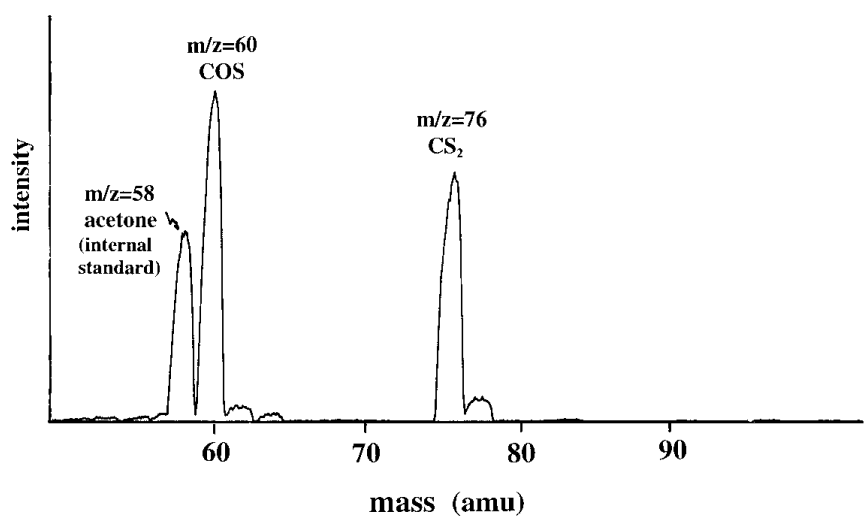

Fig. 1. Mass spectrum of the volatiles, $\mathrm{COS}$ and $\mathrm{CS}_{2}$, evolved from sample 1 in HS/MS measurement.

Figure 4 shows the evolution of COS and $\mathrm{CS}_{2}$ in the same temperature domain for the pressure cooker gasket, sample 1. Both gases are evolved simultaneously although with a slight delay for $\mathrm{CS}_{2}$. The latter is the major gas evolved for temperatures over about $75^{\circ} \mathrm{C}$. Further measurements show that the emission of these two gases keep up to temperatures of about $300-350{ }^{\circ} \mathrm{C}$ but the present study is limited to temperature ranges corresponding to domestic use of the materials. 


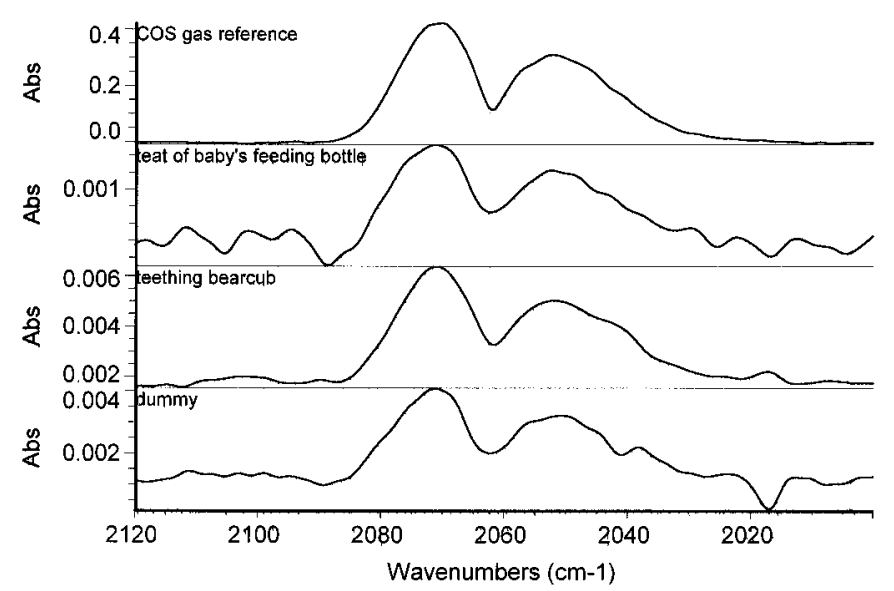

Fig. 2. Infra-red spectra of the volatiles evolved from samples 1 and 20 to 23 together with the COS reference.

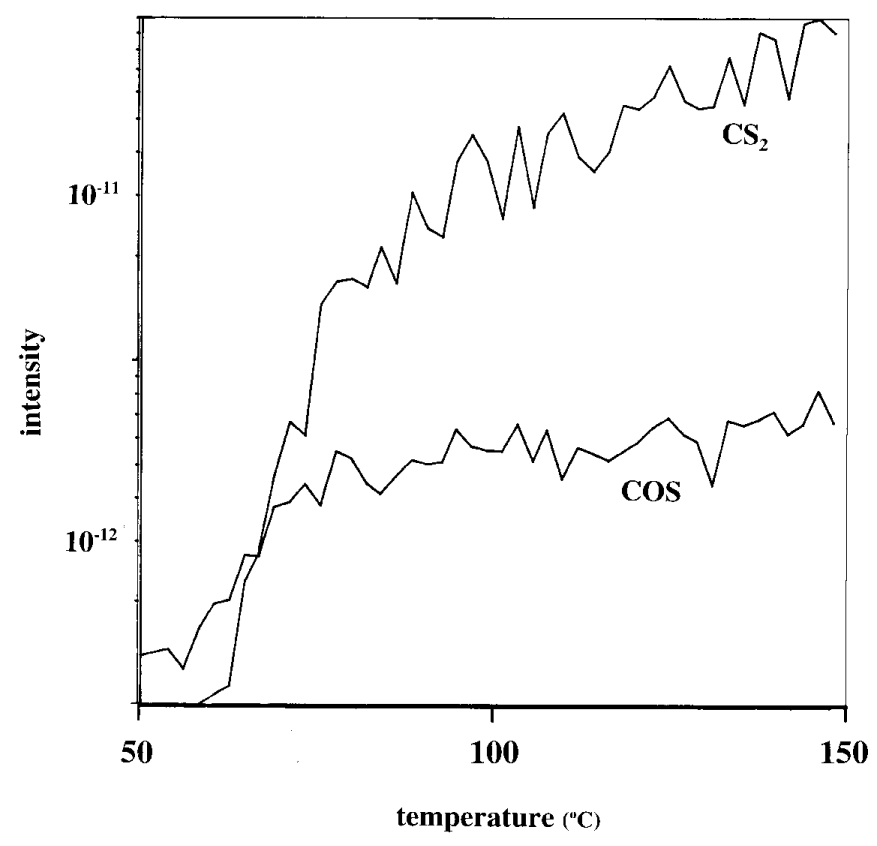

Fig. 4. Evolution of COS and $\mathrm{CS}^{2}$ from sample 1 as a function of temperature in PY/MS measurement.

\section{Quantification}

Using thermogravimetry, TGA, themobalance Mettler TG50, between 30 and $150{ }^{\circ} \mathrm{C}$, we determined weight losses of $0.36 \%$ for sample 21 (teethingh bearcub) anf of $0.39 \%$ for sample 1 (pressure cooker gasket). Those values represent the total emission of volatiles from these two samples.

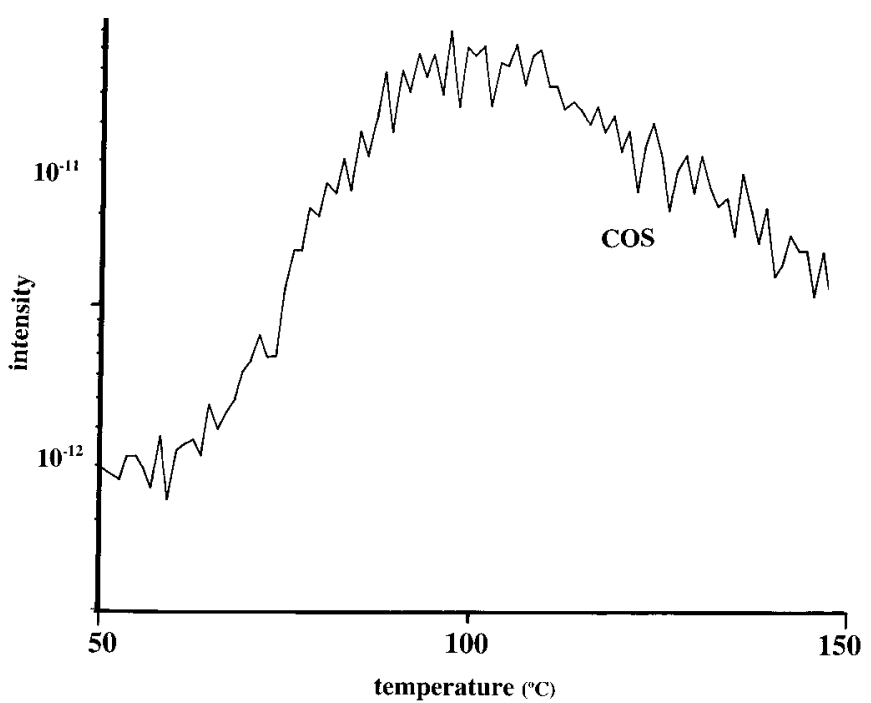

Fig. 3. Evolution of COS from sample 21 as a function of temperature in PY/MS measurements.

The quantitation of the results obtained by HS/MS and HS/FTIR was performed using samples of pure COS. For sample 21 (teething bearcub) we determined an emission of the order of $1.5 \mathrm{ppm}$ using MS and of about $2.1 \mathrm{ppm}$ using FTIR. We thus conclude that this sample emits about $1.8 \mathrm{ppm}$ of carbonyl sulfide, COS.

\section{Conclusions}

Whereas the toxicity of $\mathrm{CS}_{2}$ is relatively well documented, that concerning COS is more sparse. A detailed report on the toxicity of $\mathrm{CS}_{2}$ has been published in 1982 [1]. It is shown that $\mathrm{CS}_{2}$ can enter the human body by inhalation or by permeation through the skin. A fraction is rejected via the lungs whereas another fraction can be metabolized by the kidneys. In the course of metabolization, $\mathrm{CS}_{2}$ is oxidatively desulfurated to form $\mathrm{COS}$ and then $\mathrm{CO}_{2}$ while liberating sulfur:

$$
\mathrm{CS}_{2} \rightarrow \mathrm{COS} \rightarrow \mathrm{CO}_{2}
$$

Pathological studies carried out on animals showed the effects of $\mathrm{CS}_{2}$ to occur principally on the nervous system, the cardiovascular system and on the liver. Genotoxicity and carcinogenicity were also studied, Various effects on the human body were also observed, e.g. on the eyes, on coronary diseases and possibly inducing genetic toxicity.

The recommended tolerated doses in 1982 have a value of $20 \mathrm{ppm}$ by inhalation whereas in the USSR, maximum concentration values (MAC) of $0.01 \mathrm{ppm}$ and average values of $0.003 \mathrm{ppm}$ were tentatively recommended.

According to the NAZ/CENAL files edited by the CNA, Caisse Nationale d'Assurance Suisse, $\mathrm{CS}_{2}$ belongs to the 


\section{Original articles}

toxicity class 1 . The higher value for working conditions is set at $10 \mathrm{ppm}$ and the lethal value by oral human ingestion has been set at $14 \mathrm{ppm}$. The toxicity limit for aqueous solution tested on fish is on the order of $100 \mathrm{ppm}$.

As already mentioned, the toxicity of COS is sparsely documented. COS belongs to the toxicity class 2 . A threshold toxicity value of $23 \mathrm{ppm}$ is cited for the toxicity on mammals, but, to our knowledge, there is no tolerance value that could be compared with the multiple test values reported for $\mathrm{CS}_{2}$.

To conclude, we could show the urgency for updating the knowledge on the toxicity of carbonyl sulfide and to set tolerance limits for this compound. While the emission of sulfur gases from gaskets used in domestic applications do not seem to present a severe hazard for the population, it looks like there has to be a great concern about the emission from teats and dummy-like items daily sucked by infants. We consider that action from the official laboratories be of uppermost priority.

\section{Acknowledgements}

Financial support from the Fonds National Suisse pour la Recherche Scientifique and from the Centre d'études et de Transferts Technologiques (CeTT) of the Ecole d'Ingénieurs du Canton de Vaud is gratefully acknowledged.

The authors thank the Chimiste Cantonal du Canton de Vaud, Dr. B. Klein, for stimulating discussions and Ms. Clémentine Blazy and Ms. Olivia Wahlen for technical assistance.

\section{Reference}

1. Beauchamp, Jr., R. O.; Bus, J. S.; Popp, J. A.; Boreiko, C. J.; Goldberg, L. "A Critical Review on Carbohn Disulfide Toxicity", Critical Reviews in Toxicology, 1982, 11, Goldberg, L. Ed., CRC Press, Boca Raton; pp 169-278. 